\title{
Hyperbaric Oxygen Therapy: Focus
}

\author{
Ahmed Amine El Oumri ${ }^{1,2}$, Hiba Badi' ${ }^{1}$, Saloua Khaloufi ${ }^{3}$ \\ ${ }^{1}$ Physical Medicine and Rehabilitation Unit, Oujda University Hospital, Oujda, Morocco \\ ${ }^{2}$ Faculty of Medicine, Oujda, Morocco \\ ${ }^{3}$ Physical Medicine and Rehabilitation Unit, HMVIM, Rabat, Morocco \\ Email: aa.eloumri@gmail.com
}

How to cite this paper: El Oumri, A.A., Badi, H. and Khaloufi, S. (2018) Hyperbaric Oxygen Therapy: Focus. Open Journal of Emergency Medicine, 6, 15-20. https://doi.org/10.4236/ojem.2018.61003

Received: December 13, 2017

Accepted: March 24, 2018

Published: March 27, 2018

Copyright $\odot 2018$ by authors and Scientific Research Publishing Inc. This work is licensed under the Creative Commons Attribution International License (CC BY 4.0).

http://creativecommons.org/licenses/by/4.0/

\section{(c) (i) Open Access}

\begin{abstract}
Hyperbaric oxygen therapy is now an integral part of the current therapeutic arsenal, it is a treatment that has a large number of indications and which concerns several specialties. This development aims to summarize some main indications.
\end{abstract}

\section{Keywords}

Hyperbaric Oxygen Therapy

\section{Definition}

Hyperbaric oxygen therapy is a mode of therapy that involves working at pressures three to four times higher than atmospheric pressure. These pressures are reached in a sealed chamber called hyperbaric therapeutic chamber. The treatment involves inhaling pure oxygen (100\%) through a face mask into a patient placed in a hyperbaric chamber at a higher than normal atmospheric pressure (760 mm Hg or 1ATA). The pressure inside the box can reach 4 bars [1].

\section{Mechanisms of Action}

Several mechanisms are associated during the intermittent exposure of oxygen under pressure. The most important mechanisms are: "the Hyperpressionhyperbarie", the hyperventilation, "the anti-infective effect", the healing effect.

\section{The Main Indications}

\subsection{Acute Poisoning by Carbon Monoxide}

This is the most frequent and most studied situation. The risk of death is about $5 \%$. Currently the majority of deaths occur at home, even before the victim has been hospitalized. In addition to the usual symptomatic measures, the basic 
treatment for any acute oxy-carbon poisoning is pure oxygen, in the mask, or by the ventilator in ventilated patients, for a period of six to 12 hours [2] [3], started on the very place of intoxication. The main objective of HBOT, which is therefore complementary to normobaretraditional oxygen therapy (ONB), is to avoid secondary neurological signs that may appear immediately, or after a free interval of a few days to a month. These manifestations can be serious and correspond to the old descriptions of the "secondary syndrome".

\subsection{Spinal Decompression Accidents in Scuba Diving}

The decompression accident is a diving accident whose evolution is unpredictable in the first 24 hours with a significant risk of neurological sequelae. The symptomatology of spinal cord decompression is related to the occurrence of acute ischemia of the spinal cord whose origin is still imperfectly understood. The most probable hypothesis is based on the concept of bullae venous engorgement at the level of the epidural plexuses with blood stasis and upstream ischemia [4]. The formation of bubbles in situ in the white matter which compresses and dilacerates the nervous tissue [5], or the appearance of a downstream ischemia by arterial air embolism [6] are other mechanisms proposed, not exclusive of the theory of venous infarction.

The treatment is based on oxygen therapy and helps to fight against tissue hypoxia by increasing the amount of oxygen dissolved in the blood. It also allows faster removal of the diluent gas dissolved in the tissues. Normobaric oxygen therapy administered at the outlet of water, showed its interest with total disappearance of clinical signs before recompression in $25 \%$ of cases, and a reduction in long-term sequelae compared to non-oxygenated patients [7].

Oxygen in hyperbaric conditions (recompression) would have a specific beneficial effect on ischemia-reperfusion and endothelial dysfunction by inhibiting adhesion to leukocytes and NO [8].

\subsection{Iatrogenic Gas Embolism}

The incidence of iatrogenic gaseous embolism is difficult to assess because this accident is often unknown. The clinical manifestations are varied, variable in time and nonspecific [9]. The diagnosis is certain only when one objects the passage of gas in the systemic circulation. Nevertheless, any suspicion of air embolism is a formal and urgent indication for hyperbaric oxygen therapy. As for carbon monoxide poisoning, the treatment is based on the suppression of the exposure to risk, the maintenance of major vital functions, and oxygen therapy to a $100 \%$ oxygen inspired fraction of the face mask or, where appropriate, in mechanical ventilation [10]. In pure oxygen, the denitrogenation of the blood allows the reduction of the size of the air bubbles, by simple diffusion of the nitrogen. In addition, the increase in dissolved oxygen makes it possible to cover the tissue energy requirements. Monobaric oxygen therapy must be initiated as soon as the diagnosis of gas embolism is suspected, and the patient is transferred to a center of HBOT, in addition to the acceleration of the beneficial effects of 
oxygen, hyperbaria can reduce the size bubbles by a mechanical effect.

\subsection{Soft Tissue Infections}

Soft tissue infections represent a medical and surgical emergency whose incidence is poorly understood. The role of HBOT in adjunct to antibiotic therapy and surgery is discussed [11] [12]. The least controversial indication of HBOT is mycloecal secretion. Yet again the level of evidence is low. Anaerobic germs, in particular Clostridium perfringens, are extremely sensitive to oxygen. At a partial pressure of 90 to $250 \mathrm{mmhg}$ oxygen exerts a bacteriostatic effect. When the exposure to oxygen in a hyperbaric medium is sufficiently prolonged, the rise in oxidation-reduction potential causes a reduction in protein synthesis and induces the formation of oxygen free radicals which may be responsible for bacterial lysis.

\section{Other Indications}

\subsection{Autism}

Autism is the most common Pervasive Developmental Disorder (PDD). It is a disorder characterized by early deficits in the overall development of cognitive, verbal and relational functions.

Many studies in the medical literature demonstrate hypoperfusion of several areas of the brain of autists and more particularly of the temporal lobes. This hypoperfusion may affect up to $86 \%$ of autistic individuals [13], several studies have shown that not only children with autism had a decreased baseline blood flow, but that there was no increase in blood flow when the brain cells had to provide more work. Hypo cerebral perfusion causes hypoxia, which triggers an electrical failure of the brain cells.

$\mathrm{HBO}$ is therefore potentially effective in disorders that respond to a model of cerebral hypoperfusion. In addition to cerebral hypoperfusion, a study published in 2005 shows at autopsy that children with autism have cerebral inflammation [14]. HBOT may be useful because of its anti-inflammatory effects [15]. The repetition of HBOT sessions also allows the stimulation of free radical scavengers, likely to block the initiation of pro-inflammatory state. These anti-inflammatory effects were compared to the action of Diclofenac in an animal study using $\mathrm{HBO}$ at 2.4 ATA and $100 \%$ oxygen [16].

\subsection{The Brutal Deafness}

Sudden deafness is a controversial indication. For doctors who advocate the interest of HBOT, the indication is based on the fact that HBOT increases the oxygen partial pressure in the inner ear [17], improves blood viscosity and elasticity globular [18]. A review of the literature suggests a potential benefit of HBOT in cases of sudden refractory deafness after two weeks of vasodilator therapy and/or corticosteroids, provided that treatment is given within three months of onset [19]. However, this review of the literature does not differen- 
tiate idiopathic deafness from traumatic, vascular or infectious deafness.

\subsection{Cerebral Ischemia}

Cerebral ischemia is one of the common denominators of all acute cerebral lesions, whether vascular or traumatic. Hyperbaric oxygen therapy (HBOT) could replace this oxygen deficiency and reverse a theoretically reversible process of ischemia before the formation of definitive lesions. Indeed, in experimental models of head trauma or cerebral ischemia, HBOT has a neuroprotective effect linked to various mechanisms such as the modulation of oxidative stress, inflammation and particularly mitochondrial brain metabolism. However, clinical trial results have been disappointing for cerebral ischemia and uncertain for head trauma. The possibility of combining inert gases at the HBOT session, in particular argon or xenon which has experimentally proven their neuroprotective effects, could bring an additional benefit in the improvement of brain lesions. Nevertheless, better targeted, multi-center and good quality studies are needed before definitively being sure of the efficacy of HBOT and the addition of an inert gas in the neuroprotection of acute brain lesions [20].

\subsection{Radiation Cystitis}

Radiation hemorrhagic cystitis remains a serious complication of pelvic radiotherapy [21], which may require haemostatic cystectomy when conservative treatments have failed [22]. To date, hyperbaric oxygen therapy (HBOT) remains the only etiological treatment that acts by improving vascularization and thereby allowing bladder scarring [23]. HBO has been known for more than 60 years to improve these radiation lesions [24]. This treatment is not used in first intention in a majority of cases given the poor availability of hyperbaric chambers [25].

\section{Conclusions}

Hyperbaric Oxygen Therapy is a mode of therapy that combines the effects of pressure and those of oxygen. Its mechanisms of action follow the indications of the HBOT which are very multiple and varied.

Its efficacy is proven for certain acute or chronic diseases; other indications are being evaluated, but suggest a possible enlargement of the field of activity of НВОТ.

\section{References}

[1] Houman, R. (2003) Management of Fire Risks in Hospital Hyperbaric Environments. European Journal of Underwater and Hyperbaric Medicine, 3, 87-88.

[2] Mathieu, D., Mathieu-Nolf, M. and Wattel, F. (1996) Intoxication par le monoxyde de carbone: Aspects actuels. Bull Acad Natle Méd, 180, 965-973.

[3] Raphael, J.C., Jars-Guincestre, M.C. and Gajdos, P. (1992) Intoxication aiguë par le monoxyde de carbone. Réanimation Urgences, 1, 723-735. https://doi.org/10.1016/S1164-6756(05)80025-8 
[4] Hallenbeck, J.M., Bove, A.A. and Elliott, D.H. (1975) Mechanisms Underlying Spinal Cord Damage in Decompression Sickness. Neurology, 25, 308-316. https://doi.org/10.1212/WNL.25.4.308

[5] Marzella, L. and Yin, A. (1994) Role of Extravascular Gas Bubbles in Spinal Cord Injury Induced by Decompression Sickness in the Rat. Experimental and Molecular Pathology, 61, 16-23. https://doi.org/10.1006/exmp.1994.1022

[6] Wilmshurst, P. and Bryson, P. (2000) Relationship between the Clinical Features of Neurological Decompression Illness and Its Causes. Clinical Science, 99, 65-75. https://doi.org/10.1042/cs0990065

[7] Longphre, J.M., Denoble, P.J., Moon, R.E., Vann, R.D. and Freiberger, J.J. (2007) First Aid Normobaric Oxygen for the Traitment of Recreational Diving Injuries. Undersea Hyperb Med, 34, 43-49.

[8] Thom, S.R. (2004) Effects of Hyperoxia on Neutrophil Adhesion. Undersea Hyperb Med, 31, 123-131.

[9] Bacha, S., Annane, D. and Gajdos, P. (1996) Les emboliesgazeusesiatrogènes. Presse Med, 25, 1466-1472.

[10] Durant, T.M., Long, J. and Oppenheimer, M.J. (1947) Pulmonary Venous Air Embolism. American Heart Journal, 33, 269-281. https://doi.org/10.1016/0002-8703(47)90656-X

[11] Conférence de Consensus (2000) Erysipèle et fasciite nécrosante: Prise en charge. Médecine et Maladies Infectieuses, 30, 252-272. https://doi.org/10.1016/S0399-077X(01)80012-3

[12] Annane, D., Clair, B., Faye, A., Salah, A. and Gajdos, P. (2002) Infections sévères de la peau et des tissus mous. In: Charbonneau, P., Praz, G. and Glausera, M., Eds., Pathologies infectieuses en réanimation, Elsevier, Paris, 426-452.

[13] Zilbovicius, M., Boddaert, N., Belin, P., et al. (2000) Temporal Lobe Dysfunction in Childhood Autism: A PET Study. Positron Emission Tomography. American Journal of Psychiatry, 157, 1988-1993. https://doi.org/10.1176/appi.ajp.157.12.1988

[14] Vargas, D.L., Nascimbene, C., Krishnan, C., et al. (2005) Neuroglial Activation and Neuroinflammation in the Brain of Patients with Autism. Ann Neurol, 57, 67-81. https://doi.org/10.1002/ana.20315

[15] Al-Waili, N.S. and Butler, G.J. (2006) Effects of Hyperbaric Oxygen on Inflammatory Response to Wound and Trauma: Possible Mechanism of Action. Scientific-World Journal, 6, 425-441. https://doi.org/10.1100/tsw.2006.78

[16] Sumen, G., Cimsit, M. and Eroglu, L. (2001) Hyperbaric Oxygen Treatment Reduces Carrageenan-Induced Acute Inflammation in Rats. European Journal of Phar macology, 431, 265-268. https://doi.org/10.1016/S0014-2999(01)01446-7

[17] Lamm, C.H., Walliser, U., Schumann, K. and Lamm, K. (1988) Sauerstoff-PartialdruckMesungen in der Perilymphe der Scala tympani unternormo-und hyperbaren Bedingungen. $H N O, 36,363-366$.

[18] Pilgramm, M., Roth, M. and Fischer, B. (1988) DerEinfluss der hyperbaren Oxygenation auf rheologische Parameter. Perfusion, 2, 79-82.

[19] Lamm, K., Lamm, H. and Arnold, W. (1998) Effect of Hyperbaric Oxygen Therapy in Comparison to Conventional or Placebo Therapy or No Treatment in Idiopathic Sudden Hearing Loss, Acoustic Trauma, Noise-Induced Hearing Loss and Tinnitus. A Literatur Esurvey. Advances in Oto-Rhino-Laryngology, 54, 86-99. https://doi.org/10.1159/000059055

[20] 2013 SFAR Société Française d'Anesthésie et de Réanimation. Publié par Elsevier 
Masson SAS.

[21] Heemsbergen, W.D., Peeters, S.T.H., Koper, P.C.M., Hoogeman, M.S. and Lebesque, J. (2006) Acute and Late Gastrointestinal Toxicity after Radiotherapy in Prostate Cancer Patients: Consequential Late Damage. International Journal of Radiation Oncology, Biology, Physics, 66, 3-10. https://doi.org/10.1016/j.ijrobp.2006.03.055

[22] Rigaud, J., Hetet, J.F. and Bouchot, O. (2004) Prise en charge de la cystite radique. Progres En Urologie, 14, 568-572.

[23] Oxygénothérapie hyperbare. Rapport de la haute autorité de santé du 31 janvier 2007.

[24] Marx, R.E., Ehler, W.J., Tayapongsak, P. and Pierce, L.W. (1990) Relationship of Oxygen Dose to Angiogenesis Induction in Irradiated Tissue. The American Journal of Surgery, 160, 519-524. https://doi.org/10.1016/S0002-9610(05)81019-0

[25] Pires, C., Irani, J., Ouaki, F., Murat, F.J. and Doré, B. (2002) Oxygénothérapie hyperbare et cystite hémorragique post-radique. Progres En Urologie, 12, 1188-1193. 